\title{
Maintenance Scheduling Method of Equipments Based on Deterioration Prediction and Reliability
}

\author{
Satoru GOTO and Masatoshi NAKAMURA \\ Department of Advanced Systems Control Engineering, Saga University \\ Honjomachi, Saga 840-8502, JAPAN \\ Tel +81-952-28-8643, Fax +81-952-28-8666, E-mail goto@ee.saga-u.ac.jp
}

\begin{abstract}
In recent years, various kinds of maintenance jobs of equipments exist for the purpose of maintaining reliability for stable operation of equipments, improving efficiency as well as reducing total cost. However, maintenance jobs are usually carried out based on experience of experts and/or regulations, in some cases, without evaluation based on quantitative measurement of deterioration nor explicit decision criterion of deterioration. In this research, decision making method of maintenance scheduling, which is suitable for various kinds of equipments, was proposed. The proposed method was applied to analysis on the judgment of replacement and/or reparation of equipments in a thermal power station.
\end{abstract}

\section{Introduction}

Maintenance is important work for various systems in order to keep stable operation of the systems. Frequent maintenance gives high reliability of the systems, but maintenance cost will be increased. On the other hand, malfunction of the systems caused by lack of maintenance gives serious problems. Hence, maintenance will be decided on the balance of cost and reliability.

Many researches of maintenance problems have been investigated for various problems[1]-[11]. The authors have also proposed maintenance decision making method for timely washing of substation insulators $[12,13,14]$.

In this research, the previously proposed decision-making method of maintenance was generalized for various kinds of equipments[17, 18, 19]. The proposed method can be adopted for any kinds of equipments due to its general consideration of the judgment of replacement and reparation.

\section{Method}

\subsection{Outline of Maintenance Scheduling}

Purpose of maintenance scheduling is to keep the system reliability and reduce the total cost including maintenance, by avoiding excess repair and replacement. Deterioration prediction of the system is introduced for maintenance scheduling based on the deterioration prediction model and the reliability is taken into account by the confidence interval of prediction.

Figure 1 shows the flow chart of the proposed maintenance scheduling method. The proposed maintenance scheduling method is done by following steps.

1. Deterioration of the system occurs.

2. Deterioration of the system is measured as $y_{t}$ (deterioration measurement value).

3. Deterioration of the system is evaluated from the deterioration measurement value as $d_{t}$ (deterioration management value).

4. Future deterioration of the system is predicted by the deterioration prediction model as $\hat{d}_{t+1}$.

5. Reliability of the predicted deterioration management

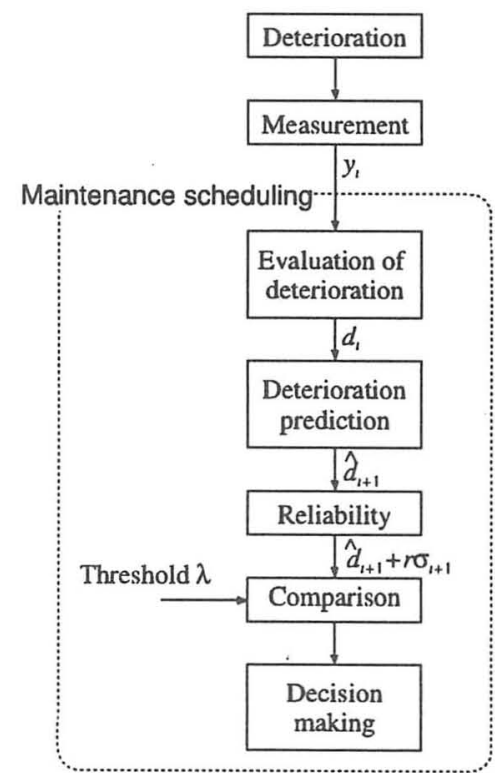

Figure 1: Flow chart of the proposed maintenance scheduling method 
value $\hat{d}_{t+1}$ is evaluated by the confidential interval as $\hat{d}_{t+1}+r \sigma_{t+1}$.

6. Maintenance is decided by comparing the confidential interval $\hat{d}_{t+1}+r \sigma_{t+1}$ and the threshold value $\lambda$.

The each step of the proposed maintenance scheduling method is explained as following subsections.

\subsection{Unification of Data Format}

Measurement data for maintenance are usually acquired with various formats, which depend on property of equipments and/or vendor of equipments. To determine maintenance decision making of various equipments in a unified method, data sets acquired from various equipments are converted into the same format $[15,16]$. The identically formatted data is referred as processed data for analysis. Figure 2 shows the unified format of processed data for analysis. The upper table in Fig. 2 shows the format of the processed data for analysis and the lower table shows an example of actual processed data for analysis. In the proposed maintenance scheduling method, the processed data for analysis are used as a unified format of the acquired data.

\subsection{Deterioration Evaluation Based on Deterioration Management Values}

Deterioration of equipments is observed from measurement data. Evaluation of deterioration, however, depends on the respective equipments. Measurement data $y_{t}$ at time $t$ relevant to deterioration is converted into deterioration management value $d_{t}$ as

$$
d_{t}=f\left(y_{t}\right)
$$

\subsection{Prediction of Deterioration}

\section{(a) Deterioration Related Parameters}

To construct a deterioration prediction model, parameters which affect to the deterioration management value must be known. The parameters which affect to the deterioration of the equipments and are also depend on time $t$ such as time itself, are defined by deterioration parameters $p_{t}$ as

$$
p_{t}=\left\{p_{t}^{1}, p_{t}^{2}, p_{t}^{3}, \cdots\right\}
$$

\section{(b) Data Classification by Deterioration Factors}

Factors which are related to the deterioration and are independent in time $t$ such as measurement points, are defined by deterioration factors $c$ as

$$
c=\left\{c^{1}, c^{2}, c^{3}, \cdots\right\}
$$

In some cases, the accuracy of the deterioration prediction model depends on the classification by the deterioration factors. Classification is adopted if the classified models can predict accurately compared with the non-classified models. The accuracy of the model can be evaluated by the standard deviation. If the standard deviation of the classified model $\sigma(C)$ ( $C \subseteq c$ ) is much less than that of the non-classified model $\sigma$

$$
\sigma(C) \ll \sigma
$$

the classified model is applied. Here $C$ means a classification of deterioration factor $c$.

\section{(c) Deterioration Prediction Model}

Deterioration prediction model is constructed for each deterioration factor $c^{i}$. The model is defined by the function of the past deterioration management values $\left(d_{t}\left(c^{i}\right), d_{t-1}\left(c^{i}\right), d_{t-2}\left(c^{i}\right), \cdots\right)$ and the past deterioration parameters $\left(\boldsymbol{p}_{t}\left(c^{i}\right), \boldsymbol{p}_{t-1}\left(c^{i}\right), \boldsymbol{p}_{t-2}\left(c^{i}\right), \cdots\right)$ as

$$
\begin{aligned}
\hat{d}_{t+1}\left(c^{i}\right)= & g\left(d_{t}\left(c^{i}\right), d_{t-1}\left(c^{i}\right), d_{t-2}\left(c^{i}\right), \cdots,\right. \\
& \left.p_{t+1}\left(c^{i}\right), p_{t}\left(c^{i}\right), p_{t-1}\left(c^{i}\right), \cdots\right)
\end{aligned}
$$

\subsection{Decision Making Rule for Maintenance Scheduling}

The standard deviation of the prediction

$$
\begin{aligned}
\sigma_{t+1}(C)= & h\left(\hat{d}_{t}\left(c^{j}\right), \hat{d}_{t-1}\left(c^{j}\right), \hat{d}_{t-2}\left(c^{j}\right), \cdots\right. \\
& d_{t}\left(c^{j}\right), d_{t-1}\left(c^{j}\right), d_{t-2}\left(c^{j}\right), \cdots, \\
& \left.p_{t+1}\left(c^{j}\right), p_{t}\left(c^{j}\right), p_{t-1}\left(c^{j}\right), \cdots\right), \text { where } c^{j} \in C(6)
\end{aligned}
$$

is used for the accuracy of the prediction. Deterioration prediction value $\hat{d}_{t+1}\left(c^{i}\right)$ is assumed to have some probability distribution and the confidence interval for reliability $R$ is derived as

$$
P\left(\frac{\left|d_{t+1}\left(c^{i}\right)-\hat{d}_{t+1}\left(c^{i}\right)\right|}{\sigma_{t+1}(C)}>r\right)=R .
$$

Finally, repair of the equipments is proceeded if the maximum value of the confidence interval exceeds a threshold value $\lambda$ as

$$
\begin{array}{ll}
\hat{d}_{t+1}\left(c^{i}\right)+r \sigma_{t+1}\left(c^{i}\right) \geq \lambda & \text { (deterioration increase case) } \\
\hat{d}_{t+1}\left(c^{i}\right)-r \sigma_{t+1}\left(c^{i}\right) \leq \lambda & \text { (deterioration decrease case) }
\end{array}
$$

where the threshold value $\lambda$ is given by respective equipment from its manufacturer through reliability and safety.

Figure 3 shows decision making rule for deterioration increase case. 


\begin{tabular}{|c|c|c|c|c|c|c|c|c|c|}
\hline & & & \multicolumn{7}{|c|}{$\begin{array}{l}\text { Address data } C \\
\text { (Address of measurement point, Maintenance items, etc) }\end{array}$} \\
\hline & & & \multicolumn{7}{|c|}{$\begin{array}{l}\text { Design data(Example:Threshold } \lambda \text { ) } \\
\text { (Data determined by each address, independent of time) }\end{array}$} \\
\hline : & \multicolumn{2}{|c|}{$\begin{array}{l}\text { Operation } \\
\text { data } p_{t} \\
\text { (Operation, } \\
\text { time, } \\
\text { Weather } \\
\text { condition, } \\
\text { etc,) }\end{array}$} & \multicolumn{7}{|c|}{$\begin{array}{l}\text { Data (Example: } y_{t} \text { ) } \\
\text { (Measurement value,Detection position, property, etc) }\end{array}$} \\
\hline \multicolumn{10}{|c|}{$i$} \\
\hline \multicolumn{10}{|c|}{$j$} \\
\hline \multicolumn{10}{|c|}{$k$} \\
\hline & 1 & 1 & 2 & 3 & 4 & 5 & 6 & 7 & 8 \\
\hline$t$ & $\Delta_{t}$ & $d t(1,1,1,1)$ & $d t(1,1,1,2)$ & $d t(1,1,1,3)$ & $d t(1,1,1,4)$ & $d t(1,1,1,5)$ & $d t(1,1,1,6)$ & $d t(1,1,1,7)$ & $d t(1,1,1,8)$ \\
\hline 1 & 9631 & 6.5 & \begin{tabular}{|l|}
6.4 \\
\end{tabular} & \begin{tabular}{|l|}
6.4 \\
\end{tabular} & \begin{tabular}{|l|}
6.4 \\
\end{tabular} & \begin{tabular}{|c|}
6.3 \\
\end{tabular} & \begin{tabular}{|l|}
6.4 \\
\end{tabular} & \begin{tabular}{|l|}
6.4 \\
\end{tabular} & \begin{tabular}{|l|}
6.4 \\
\end{tabular} \\
\hline 2 & 5518 & 6.3 & 6.2 & 6.2 & 6.2 & 6.1 & 6.2 & 6.2 & 6.2 \\
\hline 3 & 6748 & 6.2 & 6.0 & 6.0 & 6.1 & 6.0 & 6.2 & 6.0 & 6.2 \\
\hline 4 & 11258 & 6.2 & 6.0 & 6.0 & 6.1 & 6.0 & 6.2 & 6.0 & 6.2 \\
\hline 5 & 11319 & 6.2 & 6.0 & 6.0 & 6.1 & 6.0 & 6.2 & 6.0 & 6.0 \\
\hline 6 & 11220 & 6.1 & 5.9 & 5.9 & 6.0 & 5.9 & 5.9 & 5.9 & 6.0 \\
\hline 7 & 11823 & 6.1 & 5.9 & 5.8 & 6.0 & 5.8 & 5.9 & 5.9 & 5.8 \\
\hline 8 & 13005 & 6.1 & 5.9 & 5.8 & 6.0 & 5.8 & 5.9 & 5.8 & 5.8 \\
\hline
\end{tabular}

Figure 2: Format of the processed data for analysis in order to determine maintenance decision making of various equipments in a unified method

\section{Application to Boiler Tube in Thermal Power Station}

The proposed maintenance scheduling method was applied to boiler tube maintenance in a thermal power station.

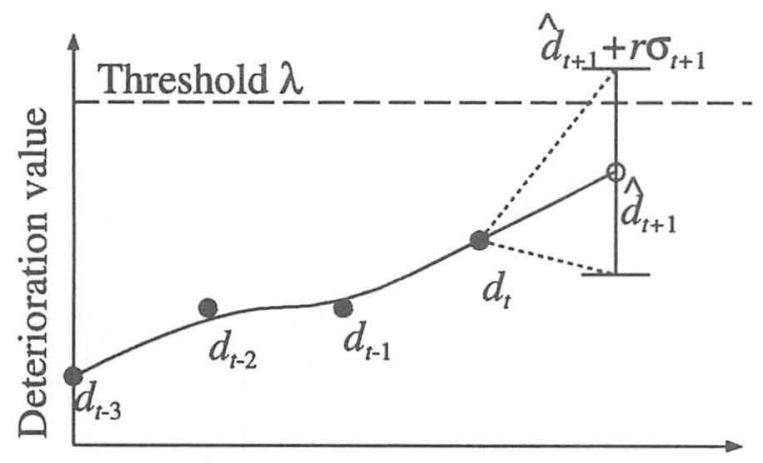

Time

Figure 3: Rule for decision making of the maintenance (deterioration increase case)

\subsection{Maintenance Scheduling}

Figure 4 shows the boiler outline in a thermal power station and its measurement points. Thickness of boiler tubes gets thinner with time. If the tubes get ripped open, the boiler suffers serious damage. Hence, the thinned tube must be repaired before broken. Deterioration of boiler tube is evaluated by its thickness. Thickness of tube is measured periodically. Data were acquired from Matsuura thermal power station in Kyushu Electric Power Co. The total data number of boiler tubes were $9504(4 \times 22 \times 3 \times 36)$ per one measurement time, and the total measurement times were 7 .

Measurement data of the boiler tube is thickness $y_{t}$ and the deterioration management value $d_{t}$ in eq.(1) is the thickness itself as

$$
d_{t}=y_{t}
$$

Deterioration related parameter $p_{t}$ in (2) for boiler tube is the time interval $\Delta_{t}$ from the previous measurement time $t-1$ to the present measurement time $t$ as

$$
p_{t}=\left\{\Delta_{t}\right\}
$$


Data classification $\boldsymbol{c}$ is the deslagger placement layer $i$, deslagger number $j$, measurement layer $k$ and measurement tube position $l$. Hence, the classification in (3) is expressed by

$$
c=\{i, j, k, l\}
$$

where

$$
\begin{gathered}
i=1,2, \cdots, I(I=4) \\
j=1,2, \cdots, J(J=22) \\
k=1,2, \cdots, K(K=3) \\
l=1,2, \cdots, L(L=36) .
\end{gathered}
$$

For the boiler tube case, the deterioration tendency depends on the measurement tube position $l$ and the other deterioration factors $i, j, k$ had little effects to the deterioration tendency, the deslagger affects to the boiler tube deterioration. Hence, the classification described in section (b) for the measurement tube position $l$ was adopted as $C^{T}=$ $\{\{1\},\{2\}, \cdots\{21\},\{22,23, \cdots, 32\},\{33\}, \cdots,\{36\}\}$. One deterioration model for the boiler tube position $l \in\{22,23, \cdots, 32\}$ was constructed and each deterioration model for the other tube position $l \notin\{22,23, \cdots, 32\}$ were constructed, respectively. The deterioration model where the deterioration was progressed in proportion with time interval was introduced. The predicted deterioration management value was calculated by

$$
\hat{d}_{t+1}(i, j, k, l)=d_{t}(i, j, k, l)+v(C) \Delta_{t+1}(l \in C)
$$

where $C \in C^{T}$ and the standard deviation $\sigma_{t+1}(C)$ was calculated as

$$
\sigma_{t+1}(C)=\Delta_{t+1} \sqrt{\frac{\sum_{u=1}^{t} \sum_{i=1}^{I} \sum_{j=1}^{J} \sum_{k=1}^{K} \sum_{l \in C}\left\{e_{u}(i, j, k, l)\right\}^{2}}{t I J K \sum_{l \in C} 1}}
$$

where

$$
e_{t}(i, j, k, l)=\frac{d_{t}(i, j, k, l)-\hat{d}_{t}(i, j, k, l)}{\Delta_{t}} .
$$

For the boiler tube case, the deterioration management value is decreased when the deterioration is progressed. Then, the final decision of tube repair is made by

$$
d_{t+1}(i, j, k, l)-r \sigma_{t+1}(C) \leq \lambda(l \in C) .
$$

\subsection{Results}

Fig. 5 shows the deterioration prediction result of one boiler tube. The boiler tube need not repair at time $t=90000$ [hour].
Table 1 shows the decision making results and standard deviations at time $t=80552$ [hour] by the non-classified model and the classified model. The results shows the effectiveness of the data classification. Table 2 shows the total results of exchange points. The results by using the non-classified deterioration prediction model were also included in Table 2 for comparison. From the results, the excessive repair was carried out for actual data. Compared with the non-classified results, the number of repair by using the proposed classified deterioration model is small under the same reliability condition. The results shows the effectiveness of the proposed maintenance scheduling method.

\section{Discussion}

\subsection{Application to Other Equipments}

In this paper, the proposed maintenance scheduling method was applied to the boiler tube maintenance in thermal power station. The method was also applied to other equipments in thermal power station such as coal pulverizer, and gave satisfactory results. We believe the proposed maintenance scheduling method can be applied not only to equipments in thermal power stations but also to general equipments which require

(a) Conceptual figure of boiler tube and non-regular part

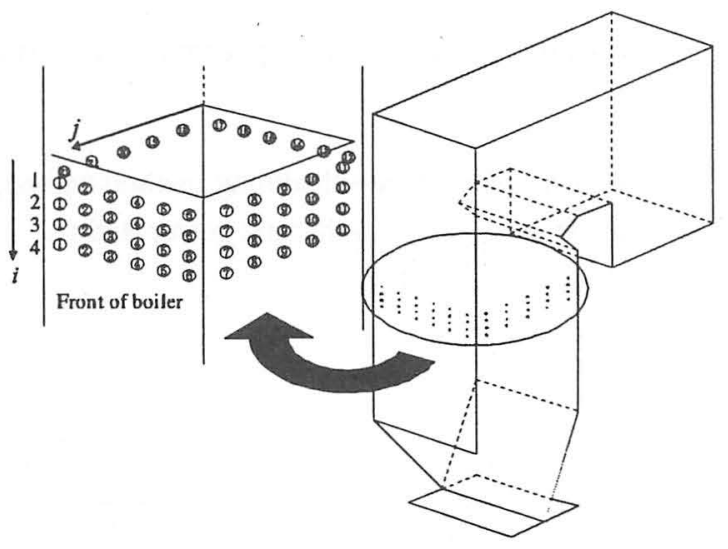

(b) Measurement point of around deslagger

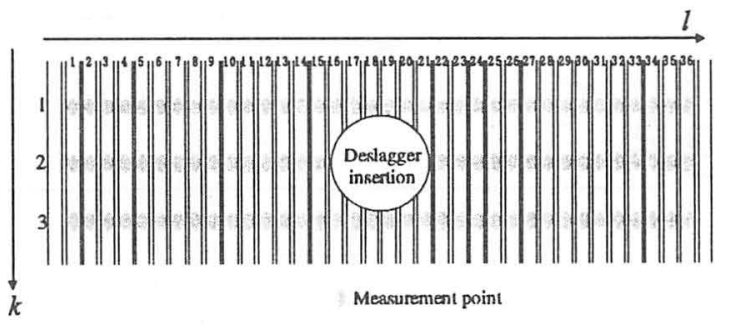

Figure 4: Measurement of boiler tube non-regular part 
Table 1: Decision making results of boiler tube maintenance at time $t=80552$ [hour]
(a) Non-classify

\begin{tabular}{|r|r|r|}
\hline$G$ & $\sigma(\mathrm{C})$ & Number of Repair \\
\hline 1 & 0.00000607 & 0 \\
\hline 2 & 0.00000603 & 0 \\
\hline 3 & 0.00000615 & 0 \\
\hline 4 & 0.00000614 & 0 \\
\hline 5 & 0.00000646 & 0 \\
\hline 6 & 0.00000652 & 0 \\
\hline 7 & 0.00000691 & 0 \\
\hline 8 & 0.00000663 & 0 \\
\hline 9 & 0.00000659 & 0 \\
\hline 10 & 0.00000648 & 0 \\
\hline 11 & 0.00000680 & 0 \\
\hline 12 & 0.00000640 & 0 \\
\hline 13 & 0.00000640 & 1 \\
\hline 14 & 0.00000595 & 0 \\
\hline 15 & 0.00000630 & 0 \\
\hline 16 & 0.00000595 & 0 \\
\hline 17 & 0.00000665 & 0 \\
\hline 18 & 0.00000632 & 0 \\
\hline 19 & 0.00000678 & 0 \\
\hline 20 & 0.00000628 & 0 \\
\hline 21 & 0.00000563 & 0 \\
\hline 22 & 0.00000703 & 0 \\
\hline 23 & 0.00000836 & 0 \\
\hline 24 & 0.00000864 & 0 \\
\hline 25 & 0.00000849 & 0 \\
\hline 26 & 0.00000827 & 0 \\
\hline 27 & 0.00000793 & 0 \\
\hline 28 & 0.00000855 & 0 \\
\hline 29 & 0.00000811 & 0 \\
\hline 30 & 0.00000775 & 0 \\
\hline 31 & 0.00000701 & 0 \\
\hline 32 & 0.00000720 & 0 \\
\hline 33 & 0.00000671 & 0 \\
\hline 34 & 0.00000652 & 0 \\
\hline 35 & 0.00000637 & 0.000651 \\
\hline 36 & 0.00000651 & 0 \\
\hline$S u m$ & & 0 \\
\hline & & 0 \\
\hline & & 0 \\
\hline
\end{tabular}

(b) Classify

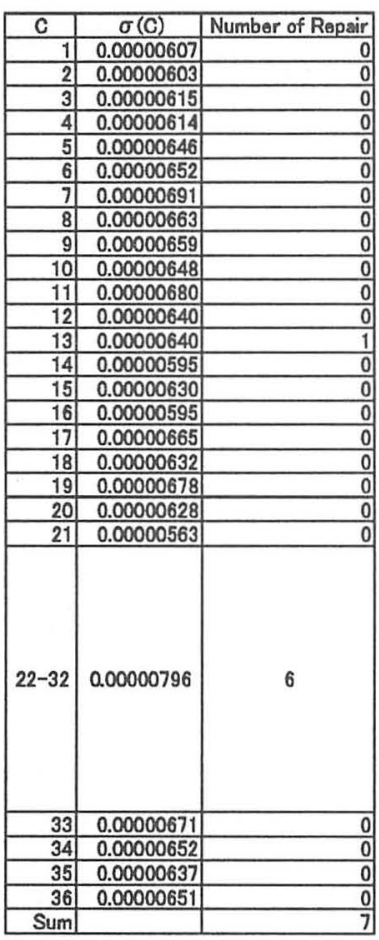

Table 2: Total results of boiler tube maintenance

\begin{tabular}{|c|c|c|c|}
\hline \multirow{2}{*}{$\begin{array}{c}\text { Time } t \\
\text { [hour] }\end{array}$} & \multicolumn{3}{|c|}{ Exchange points } \\
\cline { 2 - 4 } & Actual & Non-classify & Classify \\
\hline 55694 & 0 & 1 & 0 \\
\hline 67517 & 108 & 14 & 14 \\
\hline 80522 & 3 & 14 & 7 \\
\hline
\end{tabular}

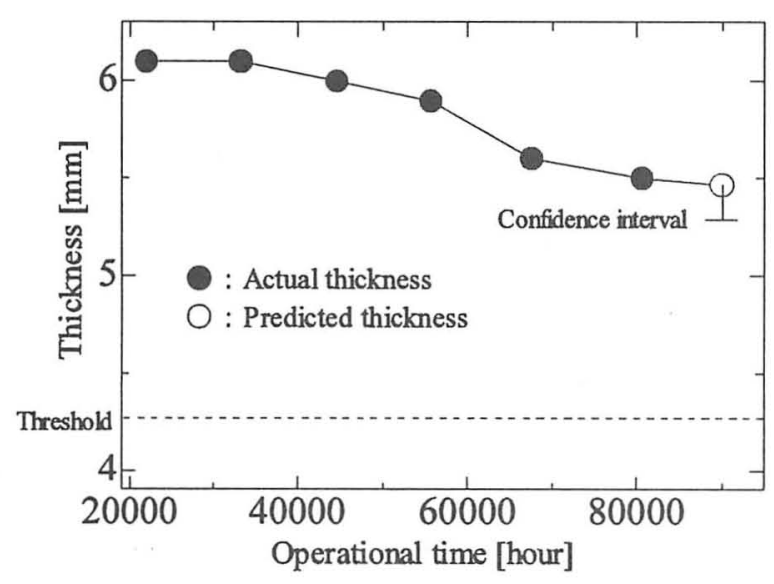

Figure 5: Prediction and decision making result for one boiler tube maintenance.

\subsection{Decision Making Rule for Maintenance Timing}

In subsection 2.5, maintenance timing of equipments is predetermined and the decision of requirement is made by the rule in (8). However, the maintenance timing is also determined by using a little modification, i.e., the rule in (8) is replaced by

$$
\hat{d}_{t^{*}}+r \sigma_{t^{*}} \geq \lambda
$$

where $t^{*}$ is the maintenance timing. Fig. 6 shows the decision making process of the maintenance timing. For the decision making of the maintenance timing, the deterioration related parameters $p_{t^{*}}$ is required.

\section{Conclusion}

Maintenance scheduling method of equipments was proposed. For the unified procedure of various equipments, acquired data were converted into the same format. Decision of maintenance was made by the deterioration prediction based on deterioration prediction model and reliability consideration based on the confidence interval.

The proposed maintenance scheduling method was applied to maintenance of boiler tubes and coal pulverizers in thermal power stations, and the number of exchanges were remarkably reduced from actual maintenance. The results show the effectiveness of the proposed maintenance scheduling method.

\section{Acknowledgement}

The authors are grateful to Mr. K. Yasukouchi, Saga University for his computer programming and M. Shirakibara, Kyushu Electric Power Company, Inc., for his valuable comments and data acquisition.

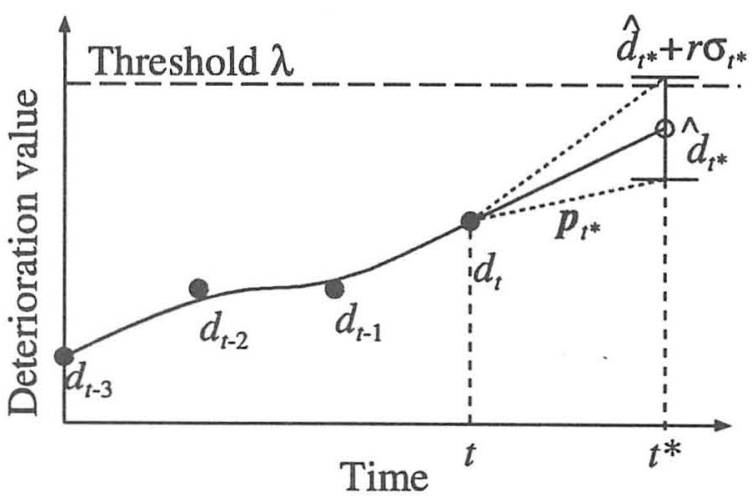

Figure 6: Decision making of maintenance timing 


\section{References}

[1] J. P. Stremel: Maintenance Scheduling for Generation System Planning", IEEE Trans. on Power Apparatus and Systems, 100, 1410/1419 (1981).

[2] J. P. Stremel and R. T. Jenkins: Maintenance Scheduling under Uncertainty", IEEE Trans. on Power Apparatus and Systems, 100, 460/465 (1981).

[3] Z. Yamayee: A Computationally Efficient Optimum Maintenance Scheduling Method", IEEE Trans. on Power Apparatus and Systems, 102, 330/338 (1983).

[4] D. Chattopadhyay, K. Bhattacharya and J. Parikh: A Systems Approach to Least-Cost Maintenance Scheduling for an Interconnected Power System", IEEE Trans. on Power Systems, 10, 2002/2007 (1995).

[5] D. Chattopadhyay: A Practical Maintenance Scheduling Program: Mathematical Model and Case Study, IEEE Trans. on Power Systems, 13, 1475/1480 (1998).

[6] R. Billinton and J. Pan: Optimal Maintenance Scheduling in a Parallel Redundant System Consisting of Series Components in Each Branch, IEEE Trans. on Power Delivery, 14, 928/933 (1999).

[7] G. Bretthauer, T. Gamaleja, E. Handschin, U. Neumann and W. Hoffmann: Integrated Maintenance Scheduling System for Electrical Energy Systems, IEEE Trans. on Power Delivery, 13, 655/660 (1998).

[8] R. Mukherjee: Power Plant Maintenance Scheduling: Optimizing Economics and Reliability, IEEE Trans. on Power Systems, PWRS-6, 476/483 (1991).

[9] L. M. Moro and A. Ramos: Goal Programming Approach to Maintenance Scheduling of Generating Units in Large Scale Power Systems, IEEE Trans. on Power Systems, 14, 1021/1028 (1999).

[10] V. Jayabalan: Cost Optimization of Maintenance Scheduling for a System with Assured Reliability, IEEE Trans. on Reliability, 41, 21/25 (1992).

[11] T. Fujiwara: Preventive Maintenance and Diagnosis and Evaluation Technique of Life for Fossil-fired Power Boilers, Karyokugenshiryoku Hatsuden, 52, 9, 1099/1108 (2001) (in Japanese)

[12] S. Goto, M. Nakamura, N. Nanayakkara and T. Taniguchi: Accurate Decision-making for Timely Washing of Substatin Insulators, Based on a Pollution Model, Control Engineering Practice, 5, 12, 1683/1689 (1997).

[13] T. Taniguchi, K. Izutsu, S. Goto and M. Nakamura: Automatic Decision Making of Washing Timing for the Pol- luted Insulators in Coastal Substations Using the Discriminant Function Based on the Conditional Probability, Transaction of IEE Japan, 118-B, 5, 593/598 (1998).

[14] M. Nakamura, W. Huang, S. Goto and T. Taniguchi: Determination of Timing for Measurement and Washing of Polluted Insulators in Substation, Transaction of IEE Japan, 122-B, 2, 314/322 (2002).

[15] R. Cooke and T. Bedford: Reliability Databases in Perspective, IEEE Transactions on Reliability, 51, 3, 294/310 (2002)

[16] M. Nakamura, H. Koki, S. Goto and H. Hatazaki: Method for Data Allocation for Analysis and Maintenance of Equipment in Thermal Power Stations, Preprints of the 21st SICE Kyushu Annual Conference, 93/96 (2002) (in Japanese)

[17] M. Nakamura, D. Hanato, S. Goto and H. Hatazaki: Maintenance Scheduling Based on Prediction and Its Variance of Deterioration of Equipment in Thermal Power Stations, Preprints of the 21st SICE Kyushu Annual Conference, 89/92 (2002) (in Japanese)

[18] K. Yasukouchi, S. Goto, M. Nakamura and M. Shirakibara: Unification of Preservation Plan Based on Deterioration Prediction of Equipments in Thermal Power Plants, Preprints of 2003 Denkikankeigakkai Kyushu Branch (2003) (in Japanese)

[19] K. Yasukouchi, S. Goto, M. Nakamura and M. Shirakibara: Accuracy Improvement of Unified Preservation Plan Based on Deterioration Prediction of Equipments in Thermal Power Plants, Preprints of the 22nd SICE Kyushu Annual Conference (2003). (in Japanese) 